\title{
Cuidados realizados pela equipe de enfermagem aos pacientes que sofreram queimaduras
}

\section{Nursing staff care to patients who suffered burns}

\section{Cuidados realizados por el equipo de enfermería a los pacientes que sufrieron quemaduras}



\author{
Isabela Lacerda Rodrigues da Cunha ${ }^{1}$ \\ Lúcia Aparecida Ferreira ${ }^{2}$ \\ José Henrique da Silva Cunha ${ }^{3}$
}

O objetivo deste estudo foi descrever e analisar a assistência de profissionais de enfermagem no cuidado aos pacientes que sofreram queimaduras. Trata-se de um estudo descritivo com abordagem qualitativa, desenvolvido com enfermeiros e técnicos de enfermagem do Hospital de Clínicas da Universidade Federal do Triângulo Mineiro no período de janeiro a março de 2016. Os dados foram coletados por meio de um roteiro de entrevista semiestruturado e submetido à análise de conteúdo do tipo temática. A análise dos dados possibilitou o surgimento de quatro categorias: a) Humanização do cuidado; b) Conhecimento dos profissionais de enfermagem durante o banho; c) Conhecimento dos profissionais de enfermagem durante o curativo; d) Cuidados gerais com o paciente. Enfatiza-se a importância do enfermeiro se atualizar e de buscar conhecimento científico, com vistasa uma assistência mais adequada aos pacientes.

Descritores: Queimaduras; Enfermagem; Cuidados de enfermagem.

The objective of this study was to describe and analyze offered by nursing professionals to burned patients. This is a descriptive, qualitative study, developed with nurses and nursing technicians of the General Hospital of the Federal University of the Triângulo Mineiro, Uberaba, MG, Brazil, from January to March, 2016. Data were collected through a semi-structured interview script and analyzed via thematic content analysis. Data analysis enabled the appearance of four categories: a) general care with the patient; b) humanization of care; c) knowledge of nursing professionals during the bath; d) knowledge of nursing professionals during the dressing of injuries. It is necessary to emphasize how important it is for nurses to maintain themselves updated and aware of current with scientific knowledge, in order to provide a more adequate assistance to patients.

Descriptors: Burns; Nursing; Nursing care.

El objetivo de este estudio fue describir y analizar la asistencia de profesionales de enfermería en el cuidado a los pacientes que sufrieron quemaduras. Se trata de un estudio descriptivo con abordaje cualitativo, desarrollado con enfermeros y técnicos de enfermería del Hospital de Clínicas de la Universidad Federal do Triángulo Mineiro, Uberaba, MG, Brasil, en el periodo de enero a marzo de 2016. Los datos fueron colectados por medio de un guión de entrevista semiestructurado y revisados por el análisis de contenido del tipo temático. El análisis de los datos posibilitó el surgimiento de cuatro categorías: a) Humanización del cuidado; b) Conocimiento de los profesionales de enfermería durante el baño; c) Conocimiento de los profesionales de enfermería durante el curativo; d) Cuidados generales con el paciente. Se enfatiza la importancia de que el enfermero se actualice y busque conocimiento científico, con el objetivo de una asistencia más adecuada a los pacientes.

Descriptores: Quemaduras; Enfermería; Atención de enfermería.

1. Enfermeira. Uberaba/MG/Brasil. ORCID 0000-0001-8007-0890.E-mail: isaa_rc@hotmail.com

2. Enfermeira. Mestre em Enfermagem Psiquiátrica. Doutora em Enfermagem. Professora Associada da Universidade Federal do Triângulo Mineiro (UFTM), Uberaba/MG/Brasil. ORCID 0000-0001-6469-5444. E-mail: lap2ferreira@yahoo.com.br

3. Terapeuta Ocupacional. Acupunturista. Especialista em Saúde do Adulto na modalidade Residência Multiprofissional. Mestrando em Atenção à Saúde pela UFTM, Uberaba/MG/Brasil. ORCID 0000-0002-4255-6125

mail: josehenrique_dasilvacunha@hotmail.com 


\section{INTRODUÇÃO}

A pele, considerada o maior órgão do corpo humano, é responsável por desempenhar importantes funções, como o controle da perda de água corporal, regulação térmica, proteção contra agentes externos e proteção corporal contra atritos. Além disso, ela funciona como uma barreira protetora contra a atuação de agentes químicos, físicos ou bacterianos. É composta por duas camadas que são a epiderme e a derme ${ }^{1}$.

Este órgão pode ser afetado em decorrência de queimaduras, que são lesões causadas por agentes externos, que podem ser químicos, térmicos e/ou elétricos, gerando destruição parcial ou total da pele ${ }^{2}$. A queimadura é uma das formas mais graves de trauma que envolve crianças e adultos e representa a quarta maior causa de morte nos Estados Unidos e a quinta causa de morte acidental no mundo. No Brasil, estima-se que um milhão de indivíduos se queimem por ano, ainda que os dados sejam subnotificados ${ }^{3}$.

As queimaduras podem ser classificadas em $1^{\circ}$ grau, $2^{\circ}$ grau e $3^{\circ}$ grau. As de primeiro grau só acometem a epiderme. Geralmente sua cicatrização ocorre dentro de uma semana e normalmente não têm repercussões sistêmicas. As queimaduras de segundo grau atingem a epiderme e a derme e há formação de flictenas. Já as de terceiro grau lesam todos os elementos da pele ${ }^{4}$.

As principais causas de morte em pessoas com grandes extensões de queimadura são as infecções e a septicemia devidas à alteração da estrutura cutânea com a perda da barreira de proteção e grande carga de colonização bacteriana, uso de cateteres, tubos e dispositivos invasivos de monitoramento ${ }^{5}$.Dessa forma, a assistência de enfermagem prestada à pessoa com queimadura é complexa, necessitando de conhecimento técnico-científico para embasar a prática.

Este estudo foi realizado no Hospital de Clínicas da Universidade Federal do Triângulo Mineiro (HC-UFTM),uma vez que este é referência para 27 municípios que compõe a Macrorregião do Triângulo Sul. Pessoas que sofreram queimaduras são encaminhadas e atendidas, e este hospital apresenta alto número de atendimentos de casos de queimaduras.

O objetivo deste estudo foi descrever e analisar a assistência de profissionais de enfermagem no cuidado aos pacientes que sofreram queimaduras.

\section{MÉTODO}

Trata-se de um estudo descritivo e exploratório com abordagem qualitativa, desenvolvido com enfermeiros e técnicos de enfermagem do HC-UFTM, localizado na cidade de Uberaba-MG.

Foram realizadas entrevistas, tendo como critérios de inclusão exercer a função de enfermeiro ou técnico de enfermagem nesta instituição pública de nível terciário, nos setores da Unidade de Terapia Intensiva Adulto, Clínica Cirúrgica ou Bloco Cirúrgico; e declarar consentimento livre e esclarecido assinando o termo para participar desta pesquisa. Os critérios de exclusão adotados foram referentes aos profissionais que estavam em gozo de férias e de licença durante o período da realização da coleta de dados (janeiro a março de 2016).

A amostragem se deu por saturação, consistindo, portanto, na suspensão da inclusão de novos participantes quando os dados das entrevistas passaram a apresentar redundância ou repetição, não sendo relevante persistir na coleta ${ }^{6}$.

Realizaram-se 10 entrevistas, de forma individuale de acordo com os horários agendados pelos participantes em uma sala apropriada que estava disponível no HCUFTM. As entrevistas foram gravadas através de um aparelho celular depois de obtida permissão para tanto. Foram transcritas na íntegra e checadas duas vezes por dois pesquisadores para garantirsua fidedignidade; foi utilizado um roteiro semiestruturado, com a pergunta norteadora: "Descreva holisticamente como são realizados os cuidados ao paciente com queimadura".

Também se utilizou um questionário sociodemográfico para a coleta de dados referentes à idade, sexo, setor em que atua, tempo de atuação na enfermagem e questões 
de cuidado ao paciente que sofreu queimadura.

Os dados coletados foram analisados pelo método de análise temática, umas das modalidades da análise de conteúdo, que consiste em identificar núcleos de sentidos presentes em uma comunicação, através da verificação da presença ou frequência desses núcleos para uma articulação com os objetivos da pesquisa. A análise acontece em três etapas: a primeira consiste na leitura do material, o que possibilita a correção de rumos interpretativos ou o surgimento de novas indagações; na segunda etapa, ocorre a exploração do material, bem como, a busca por categorias; na terceira, os resultados obtidos são embasados com os referenciais teóricos ${ }^{7}$.

0 projeto de pesquisa foi aprovado pelo Comitê de Ética da Universidade Federal do Triângulo Mineiro (CEP/UFTM) de acordo com o parecer 1.193.249 de 2015.

Para garantir o anonimato dos participantes da pesquisa, eles foram designados por nomes de flores.

\section{RESULTADOS}

Participaram do estudo dez profissionais de saúde. Entre os entrevistados, cinco eram enfermeiros e cinco técnicos de enfermagem . Em relação aos enfermeiros, quatro eram do sexo feminino e um do sexo masculino, com faixa etária entre 29 e 50 anos, tempo de atuação na enfermagem de seis a trinta anos e experiência no cuidado de pessoas com queimadura de dois meses a treze anos.

Já dentre os técnicos de enfermagem, quatro eram do sexo feminino e um era do sexo masculino, com faixa etária entre 25 a 46 anos, com tempo de atuação na enfermagem entre cinco e vinte anos e experiência no cuidado às pessoas com queimadura que variou de um ano e seis meses a vinte anos.

Após a transcrição das entrevistas, a organização e a análise temática do material, quatro categorias surgiram e foram assim nomeadas: a) Cuidados gerais com o paciente; b) Humanização do cuidado; c) Conhecimento dos profissionais de enfermagem durante $o$ banho; d) Conhecimento dos profissionais de enfermagem durante o curativo.
$\mathrm{Na}$ categoria cuidados gerais com o paciente, foram criadas as seguintes subcategorias: 1) Balanço hídrico; 2) Acesso central em pacientes com queimadura grande e/ou membros superiores; 3) Isolamento reverso; 4) Uso de Equipamento de proteção individual (EPI's); 5) uso de lençóis estéreis; 6) Troca de fixações; 7) Mudança de decúbito.

A reposição volêmica bem como o balanço hídrico são cuidados importantes a serem realizados em pacientes com queimaduras:

Durante o dia a gente também observa porque nas lesões ocorre uma perda de liquido corporal, e a gente procura ficar atento na questão da diurese, porque geralmente esses pacientes queimados eles vêm com sonda vesical de demora, então a gente quantifica a diurese desses pacientes, faz o balanço hídrico, vê o quanto que está entrando e o quanto que está saindo. Se o paciente estiver consciente, orientado, deambulando, a gente quantifica em coletor aberto de diurese. (Margarida)

o paciente nos primeiros dias de queimado geralmente perde muito líquido, tem que estar atento para a diurese. o paciente perde muito líquido, geralmente a hidratação dele é um cuidado importante, estar atento à diurese, $o$ balanço hídrico. (Jasmim)

Observa-se nos relatos abaixo que o primeiro atendimento ao paciente vítima de queimadura é manter as vias aéreas permeáveis, acesso venoso de grande calibre ou acesso venoso central:

A gente tem um cuidado especial com esses pacientes porque geralmente quando é grande queimado tem que ter um acesso central. (Tulipa)

É muito difícil paciente que vem queimado, principalmente nos membros superiores com acesso periférico, então geralmente eles vêm de acesso central (...). (Azaléia)

Visando proteger os pacientes internados com queimaduras contra possíveis infecções são utilizados isolamento reverso, EPI's e lençóis estéreis:

Primeiramente, a gente admite o paciente no isolamento, ou fica em um quarto só para ele, a gente já identifica logo como paciente reverso. Sempre que for manipular $o$ paciente fazemos uso dos EPI's, principalmente durante banho e curativo. (Orquídea)

Todos os lençóis usados em pacientes queimados são estéreis para a proteção dele (a). Lençol de forrar a cama, para cobrir o paciente e secar ele (a) no banho. (Dália)

Assim como é feito com todas as pessoas internadas no hospital, a troca de fixações nos pacientes com queimaduras é realizada sempre após o banho, promovendo 
uma melhor higienização e bem-estar ao paciente:

Feito isso, terminado o banho, a gente troca todas as fixações que geralmente é feito com todos os pacientes, com queimado também não é diferente. (Dália)

Após término do banho, troca-se todas as fixações. (Peônia)

Outro cuidado realizado pela equipe de enfermagem ao paciente que sofreu queimadura é a mudança de decúbito com o objetivo de prevenir a lesão por pressão, como pode ser observado no relato abaixo:

Depois do banho, é protocolado que a gente mude sempre de um lado para o outro para não dar escara né. (jasmim)

Na categoria humanização do cuidado, observa-se que a pessoa com queimadura precisa de cuidado humanizado, sendo necessário que a equipe de enfermagem vise $o$ bem-estar deste paciente como um todo, englobando a saúde corporal e a psicológica. Assim, nesse núcleo de sentido foram elencadas as seguintes subcategorias: 1) realização de analgesia e/ou sedação durante o banho e o curativo; 2) Acompanhamento psicológico diário; 3) presença de acompanhante.

Observa-se nestas falas que cessar a dor da pessoa com queimadura durante o banho e curativo é um cuidado importante e humanizado, por isso são feitas a analgesia e/ou a sedação nesse momento:

Durante o banho do queimado é feito analgesia, pois é um procedimento muito dolorido. Analgesia aqui é feita com morfina, metadona, e fora os outros analgésicos que tem aqui no setor, como dipirona e tramal. (Azaléia)

o paciente se ele já está com a sedação, ele mantém, se ele não está com a sedação, ele está superficial, está só com a analgesia, o médico aprofunda mais essa analgesia. (Azaléia)

0 acompanhamento psicológico diário, neste caso realizado pelo profissional de psicologia que faz parte da equipe multiprofissional do HC-UFTM, auxilia notratamento do paciente com queimadura, contribuindo para a integralidade do cuidado: A gente cuida do psicológico deles, é feito um acompanhamento, a gente tem uma psicóloga aqui no setor que ela acompanha todos os dias esse paciente. (Margarida)

A psicóloga vem para estar conversando com eles, ela se abrem, eles choram, falam sobre a família, então isso faz parte também do cuidado deles. (Tulipa)

Por meio dessas falas observa-se que no hospital há um trabalho em equipe multiprofissional, contando com o apoio do profissional de psicologia para auxiliar no tratamento do paciente com queimadura, o que contribui para integralidade do cuidado.

Nota-se abaixo, nas falas dos enfermeiros, a importância da permanência de um acompanhante ou familiar da pessoa que sofreu queimadura durante o período de internação:

Quando os pacientes queimados são admitidos aqui no setor, a gente procura deixar um acompanhante né, um familiar acompanhando né, porque isso também meche muito com o psicológico do paciente. (Rosa)

Eu costumo sempre autorizar um acompanhante para ficar com esses pacientes aqui no setor, porque a internação por queimadura meche muito com eles, com a autoestima. Então isso contribui para o psicológico deles, autorizar um acompanhante. (Azaléia)

A categoria conhecimento dos profissionais de enfermagem durante o banho compreende que o banho da pessoa com queimadura é um procedimento complexo, que exige profissionais qualificados e humanizados, pois nesse momento os pacientes sentem dor. Assim, nesse núcleo foram elencadas as seguintes subcategorias: 1) técnica estéril; 2) presença do médico e da equipe de enfermagem; 3) duração do banho; 4) secagem do paciente com lençol estéril.

$\mathrm{O}$ banho é um procedimento feito com técnica estéril:

A técnica do banho é toda estéril, geralmente vai paramentar o médico, o enfermeiro, e um técnico de enfermagem, e vai ficar outro técnico como suporte para pegar alguma coisa. (Peônia)

o banho na unidade é realizado juntamente com o curativo utilizando técnica totalmente asséptica. (Azaléia)

Nota-se nas falas dos entrevistados que o banho é realizado de forma asséptica, com técnica estéril, visando proteger a pessoa com queimadura de possíveis infecções.

0 banho é um procedimento complexo e demorado, sendo realizado com a presença do médico, do enfermeiro e dos técnicos de enfermagem. Sua duração depende muito da gravidade do caso, do grau da queimadura e de sua extensão:

o banho é feito todo na técnica estéril, com os Equipamentos de Proteção Individual (EPI's). Com a presença do médico, do enfermeiro, dos técnicos". (Rosa) o banho do queimado é um banho demorado, em média uma hora, necessita da equipe de enfermagem e de um médico, normalmente residente da plástica. (Dália) 
Com a finalidade de continuar o procedimento com técnica estéril após o banho, a pessoa é envolvida com lençol estéril, protegendo-a ao máximo de possíveis infecções:

O enxágue depois, é feito com lençol estéril, a gente ajuda também. E aí começa os curativos, geralmente é usado a papaína dependendo do local, é usado as faixas estéreis, tudo estéril. Depois que o paciente está com o banhotomado a gente forra a cama com lençóis estéreis também, esses lençóis são disponíveis para a gente diariamente. (Orquídea)

Após o banho, o paciente é seco em lençol, lençol estéril né, para manter a técnica do banho asséptica. (Jasmim)

$\mathrm{Na}$ categoria conhecimento dos profissionais de enfermagem durante o curativo, compreende-se que os profissionais de enfermagem necessitam de amplo conhecimento ao estabelecer a conduta referente aos curativos em pessoas com queimaduras. Assim, nessa categoria foram elencadas as seguintes subcategorias: 1) realização do curativo feito pelo médico e pelo enfermeiro; 2) técnica estéril; 3) ação dos técnicos de enfermagem durante o curativo; 4) Papaína é utilizada em tecidos com esfacelo e/ou necrose; 5) Sulfadiazina de prata é utilizada em tecidos de granulação; 6) Ácidos Graxos Essenciais (AGE) são utilizados na pele íntegra; 7) Utilização de fibrase e AGE na face; 8) curativo oclusivo.

0 curativo com técnica estéril no HCUFTM, é realizado pelo médico e pela equipe de enfermagem, o que pode ser observado nos depoimentos abaixo:

o curativo é feito no turno da manhã, pelo residente da plástica e pelo enfermeiro, com auxílio dos técnicos. (Margarida)

$O$ curativo é feito em técnica asséptica, com os EPI's, material estéril, usando luva estéril. (Dália)

Antes e durante o curativo, os técnicos de enfermagem são responsáveis pela busca do material, preparação e organização, como pode ser observado nas seguintes falas:

Os técnicos em enfermagem ficam a cargo de preparar e organizar o material. $O$ que inclui: lençóis estéreis, kit posto contendo capote estéril, campo estéril, bacia estéril, água destilada aquecida em caixa com lâmpada, clorexidinadegermante, pomadas - normalmente papaína 3\%, 6\%, e 10\%, sulfadiazina de prata, fibrase com cloranfenicol, atadura estéril, compressa estéril. (Jasmim)

Nesse momento, os técnicos de enfermagem preparam o material. Lençóis estéreis, kit posto, pomadas mais usadas que são papaína 3\%,6\%, 10\%, sulfadiazina de prata, fibrase e AGE. Separam atadura estéril, compressa estéril, acho que só. (Lírio)

A papaína é comumente usada em tecidos que apresentem esfacelo e/ou pontos de necrose:

A pomada você tem que avaliar assim, porque a princípio quando chega para gente queimado ainda não tem fibrina e nem tecido necrótico né, ai usa sulfadiazina de prata, que é um antibiótico e quando tem, já começa a aparecer tecido de fibrina e necrose ai você vai utilizar papaína $10 \%$ nessas áreas. (Violeta)

(...)quando o paciente está assim em um estágio mais com fibrina, ai dependendo da avaliação do residente utiliza a papaína $3 \%, 10 \%, 6 \%$. (Jasmim)

A pomada Sulfadiazina de prata é utilizada em tecidos de granulação, como pode ser observado nos relatos abaixo:

Usa-se se for tecido de granulação sulfadiazina, mas isso é prescrição médica, não é prescrição de enfermagem. A parte medicamentosa é prescrição médica. (Tulipa)

Quando tem tecido de granulação, nós usamos a sulfadiazina de prata. (Violeta)

Nas falas abaixo se observa que os Ácidos Graxos Essenciais (AGE) agem na hidratação e proteção da pele, sendo usados na pele íntegra:

(...) e no corpo na pele íntegra é usado AGE para proteger a pele né. (Dália)

(...) já na pele íntegra usamos AGE para hidratar a pele. (Rosa)

Quando se faz um curativo com a presença de tecido necrótico, é importante analisar a profundidade dele, para que através da avaliação do enfermeiro a melhor conduta a ser tomada possa ser decidida:

(...) E se tiver necrose tem que analisar a profundidade, porque se for tendão não vai passar papaína. Mas se tiver um ponto de necrose dai costuma ser papaína 10\%. (Orquídea)

Tem que olhar a profundidade quando tem necrose, porque dependendo da profundidade não usa papaína. No tendão, por exemplo, não podemos usar a papaína. (Margarida)

Nota-se que quando há queimadura na face comumente são usados fibrase e/ou AGE: No rosto como é uma parte mais delicada comumente é usado fibrase né, mas também costuma ser como prescrição médica, na pele íntegra é usado AGE para proteger a pele. (Tulipa)

(...) na face a gente sempre usa fibrase, porque não pode usar papaína na face. Então mesmo tendo necrose na face não usa papaína, só fibrase. (Peônia)

Em outras regiões do corpo é feito um curativo oclusivo, a fim de proteger a ferida: Onde tiver a ferida cobre com compressa estéril e passa as faixas, dai as faixas são passadas por baixo do paciente, são faixas estéreis né. Enfaixa para o curativo ficar oclusivo né, não cair. (Jasmim) 
Em queimaduras sempre fazemos o curativo oclusivo, passamos as pomadas e enfaixamos. Só não faz curativo oclusivo em genitais ou no rosto. (Rosa)

Quando a lesão apresenta excesso de esfacelo, o desbridamento da ferida é realizado no Bloco cirúrgico.

Quando tem uma fibrina muito extensa, aí costuma ir para o bloco para fazer desbridamento, que a papaína não consegue fazer o trabalho dela então o pessoal da plástica faz esse desbridamento.(Dália)

\section{DISCUSSÃO}

A categoria cuidados gerais aborda que um dos cuidados realizados pela equipe de enfermagem logo após a admissão do paciente é puncionar um acesso venoso calibroso ${ }^{8}$.

Segundo os relatos dos profissionais de enfermagem, assim que o paciente é admitido, é puncionado um acesso venoso central. Quando há possibilidade, punciona-se um acesso venoso periférico, mas se há queimaduras em membros superiores esse acesso torna-se indisponível, optando na maioria das vezes pelo acesso central. Já o balanço hídrico representa o monitoramento de líquidos administrados e eliminados pelo paciente no hospital. Assim, incluindo a reposição de líquidos, o balanço hídrico é cuidado de suma importância em pacientes queimados 9 .

Devido às lesões causadas pelas queimaduras, são essenciais os cuidados como a monitoração de padrões respiratórios, a reposição hídrica, o observar sinais de infecção, a realização de exame físico, controle álgico, apoio psicológico, apoio nutricional, atendendo ao paciente dentro de suas necessidades por meio de abordagem multiprofissional ${ }^{5}$.

São importantes a realização do exame físico e o apoio nutricional no cuidado ao paciente com queimaduras ${ }^{5}$, mas os participantes não os relataram.

Pacientes que sofrem queimaduras apresentam intenso quadro álgico e abalo emocional. Esses fatores podem atrapalhar sua evolução durante a internação. Sendo assim, é importante que se conheça a etiologia da queimadura para escolher o tratamento terapêutico e direcionar o trabalho da equipe de enfermagem da melhor maneira possível ${ }^{9}$.
Há evidências de que a melhora no quadro de dor do paciente está relacionada com a forma na qual esses profissionais levam sua dor em consideração ${ }^{8}$. Percebe-se essa informação nas falas dos entrevistados que visavam a humanização dos cuidados por meio do acolhimento e pela terapia farmacológica. Nesse aspecto, é de suma importância que os profissionais de enfermagem façam uma avaliação da dor do paciente no intuito de minimizar a intensidade dessa sensação sensorial ${ }^{10}$. No entanto, não foi apontada pelos pesquisadosa forma como os profissionais de enfermagem avaliam a dor nos pacientes.

0 distúrbio de imagem dos pacientes que sofreram queimadura é outro aspecto importante. Geralmente, estes pacientes apresentam baixa autoestima, medo em relação ao futuro e a sua desfiguração corporal. A equipe de enfermagem deverá estar atenta e esclarecer as dúvidas desses pacientes, além de oferecer apoio emocional, o que contribui para a integralidade do cuidado ${ }^{9,11}$.

A participação da equipe multiprofissional é essencial na integralidade desse cuidado, por exemplo, com a presença do profissional de psicologia que poderá trabalhar com as habilidades de regulação emocional do paciente. Este profissional foi citado nas entrevistas como sendo uma das profissões fundamentais no tratamento aos pacientes que sofreram queimaduras.

Nas categorias dos cuidados de enfermagem durante o banho e curativo, os participantes relataram a importância da utilização dos métodos de prevenção e controle das infecções hospitalares. Sabe-se que a queimadura provoca traumas no tecido epitelial, ocasionando destruição da barreira da pele, o que pode ocasionar infecções.Uma das formas de prevenção é a utilização de EPI's, além de técnicas assépticas durante a realização de procedimentos ${ }^{8,12}$.

Os pacientes queimados são propensos às infecções hospitalares devido à perda da barreira protetora da pele; sendo assim, é utilizado o isolamento reverso ${ }^{13}$. Este isolamento é uma instalação hospitalar destinada a proteger um paciente 
imunocomprometido de possíveis infecções. São necessários um quarto privado e o uso de EPI's tais como luvas de procedimento, máscara comum e jaleco de manga longa ${ }^{10}$. No intuito de promover bem-estar e prevenir a lesão por pressão, a mudança de decúbito é realizada pela equipe de enfermagem de duas em duas horas, conforme o protocolo utilizado na instituição HC-UFTM de $2010^{11}$.

Nos tecidos que apresentam esfacelo e/ou pontos de necrose em decorrência da queimadura utiliza-se a papaína, que é um agente tópico com a função de promover o desbridamento químico, agindo como antibiótico local na parede bacteriana e sendo utilizada na terapêutica da queimadura por possuir amplo aspecto antibacteriano ${ }^{14}$. Entretanto, em queimaduras de face não se faz uso de papaína nem se houver tecido necrótico.Avalia-se, e se necessário, a fibrase é utilizada, e se hidrata a pele com AGE na pele íntegra ${ }^{12,15}$.

Os entrevistados relataram que durante a realização do curativo fazem uso da sulfadiazina de prata 1\%,tópico de escolha em queimaduras superficiais e profundas que atua contra bactérias gram negativas, gram positivas e fungos, em tecidos de granulação ${ }^{16}$. No entanto, a literatura científica diz que esse tópico danifica o tecido de granulação e o mais utilizado é a papaína ${ }^{4,17}$.

A desvantagem da papaína é seu tempo de duração, que demanda maior quantidade de troca de curativos (12-24 horas). Dependendo da quantidade de exsudato, poderá aumentar o risco de infecção hospitalar, além do desconforto provocado pela dor ao paciente ${ }^{12}$.

Outros tópicos podem ser utilizados no curativo dos pacientes que sofreram queimaduras, sendo eles o curativo de prata nanocristalina e o Acticoat Flex. 0 primeiro possibilita criar barreiras antimicrobianas e auxilia na diminuição de troca de curativos. Sua vantagem em relação à sulfadiazina 1\% é o maior tempo de duração ${ }^{18}$. Esse tópico não foi citado.

Já o Acticoat Flex é feito à base de prata nanocristalina por uma malha de poliéster flexível, levando a uma quantidade menor de trocas de curativos, traumas locais e dor ao paciente, por manter uma ação antimicrobiana com amplo espectro de liberação contínua de prata nanocristalina por no mínimo três dias (Actiocat Flex 3) ou sete dias (Acticoat Flex 7) ${ }^{19}$.

A desvantagem do uso do Acticoat Flex é o alto custo, em comparação com outros tópicos usuais como a sulfadiazina de prata. Entretanto, quando indicado corretamente, apresenta menor custo em comparação a outros como a sulfadiazina de prata, devido à menor frequência da troca de curativos e dias de internação no hospital ${ }^{18}$. Reforça-se, assim, a qualidade dessa opção de tratamento e a implementação de protocolos para coberturas mais avançadas.

\section{CONCLUSÃO}

Conclui-se que os profissionais de enfermagem preocuparam-se em realizar condutas terapêuticas que vise a integralidade do cuidado por meio de técnicas assépticas e uso de EPI's para prevenção de agravos. Além de oferecem suporte emocional através do acolhimento e do trabalho multiprofissional. Todos esses aspectos corroboram na amenização da dor e nas complicações clínicas.

Este estudo possibilitou o conhecimento sobre a assistência ao paciente queimado e ao mesmo tempo demonstrou a importância do enfermeiro se atualizar e aumentar seu conhecimento científico, a fim de proporcionar assistência mais adequada aos pacientes. Para além do cuidado oferecido pela enfermagem ao paciente que sofreu queimadura é de suma importância a atuação da equipe multiprofissional, para assegurar a integralidade do cuidado, como observado no estudo.

Ressalta-se a necessidade de se elaborar e disseminar novos estudos que envolvam a temática estudada como forma de aprimoramento para as equipes de enfermagem que atuam com pacientes queimados.

\section{REFERÊNCIAS}

1. Ministério da Saúde (Br). Secretaria de Atenção à Saúde. Departamento de Atenção Especializada. Cartilha para tratamento de 
emergência das queimaduras. Brasília, DF: Ministério da Saúde; 2012.

2. Leão CEG, Andrade ES, Fabrini DS, Oliveira RA, Machado GLB, Gontijo LC. Epidemiologia das queimaduras no estado de Minas Gerais. Rev Bras Cir Plást. 2011; 26(4):573-7.

3. Marques MD, Amaral V, Marcadenti A. Perfil epidemiológico dos pacientes grandes queimados admitidos em um hospital de trauma. Rev Bras Queimaduras. 2013; 13(4):232-5.

4.Moser H, Pereima RR, Pereima MJL. Evolução dos curativos de prata no tratamento de queimaduras de espessura parcial. Rev Bras Queimaduras. 2013; 12(2): 60-7.

5. Pinto E, Della-Flóra AM, Silva LD, Rorato TJ, Requia J, Martins ESR, et al. O sentimento e a assistência de enfermagem perante um grande queimado. Rev Bras Queimaduras. 2014;13(3):127-9.

6. Fontanella BJB, Ricas J, Turato ER. Amostragem por saturação em pesquisas qualitativas em saúde: contribuições teóricas. Cad Saúde Públ. 2008; 24(1):17-27.

7. Minayo MCS. O desafio do conhecimento: pesquisa qualitativa em saúde. 14. ed. São Paulo: Hucitec; 2014.

8. Oliveira TS, Moreira KFA, Goncalves TA. Assistência de enfermagem com pacientes queimados. Rev Bras Queimaduras. 2012; 11(1):31-7.

9.Silva BAD, Ribeiro FA. Participação da equipe de enfermagem na assistência à dor do paciente queimado. Rev Dor. 2011; 12(4):342-8.

10. Mota WM, Araújo CAL, Rosa de Oliveira AMR, Gomez DS, Silva Junior JM, Gemperli R. Critérios diagnósticos de infecção no paciente queimado. Rev Bras Queimaduras. 2014; 13(3):130-5.

11. Marques CMG, Dutra LR, Tibola J. Avaliação fisioterapêutica da cicatrização de lesões por queimaduras: revisão bibliográfica. Rev Bras Queimaduras. 2015; 14(2):140-4.

12. Moreira SS, Macedo AC, Nunes BB, Brasileiro FF, Guarizzo J, Gozzano R. et al. Implantação de nova tecnologia para otimização do atendimento em ambulatório de queimados, sem adição de custos. Rev Bras
Queimaduras. 2013; 12(2):87-102.

13. Universidade Federal do Triângulo Mineiro, Comissão de Controle de Infecção Hospitalar. Protocolos de controle de infecção: úlcera por pressão [Internet]. Uberaba: UFTM; 2015 [acesso em 18 maio 2016]. Disponível em http://www.ebserh.gov.br/documents/1477 15/0/\%C3\%9Alcera+de+press $\%$ C3\%A3o+2 015/4763370c-8128-4efa-9c9acac591a171a4.

14. Costa Filho MAR, Ferreira RB, Nunes BB, Bortolucci GAP, Proto RS, Gozzano RN, et al. Tratamento ambulatorial de queimaduras com prata nanocristalina em malha flexível: uma alternativa terapêutica. Rev Bras Queimaduras. 2012; 11(4):226-9.

15. Chaves SCS. Ações de enfermagem para reduzir os riscos de infecção em grande queimado na UTI. Rev Bras Queimaduras. 2013; 12(3):140-4.

16. Montes SF, Barbosa MH, Sousa Neto AL. Aspectos clínicos e epidemiológicos de pacientes queimados internados em um Hospital de Ensino. Rev Esc Enferm USP. 2011; 45(2):369-73.

17. Moser HH, Pereima MJL, Soares FF, Feijó R. Uso de curativos impregnados com prata no tratamento de crianças queimadas internadas no Hospital Infantil Joana de Gusmão. Rev Bras Queimaduras. 2014; 13(3):147-53.

18. Castro RJA, Leal PC, Sakata RK. Tratamento da dor em queimaduras. Rev Bras Anestesiol. 2013; 63(1):149-58.

19. Velásquez DAM, Oliveira YSA, Rinaldi AE, Fuzinatto FF, Godoy GRS. Tratamento de queimadura grave em membros inferiores realizado em centro hospitalar não especializado em queimaduras. Rev Bras Queimaduras. 2014; 13(2):114-8.

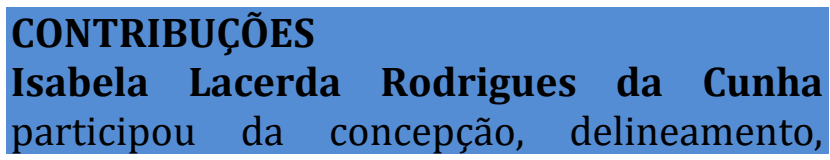


análise, coleta de dados, interpretação dos dados e redação, Lúcia Aparecida Ferreira atuou na concepção, delineamento, análise, crítica e José Henrique da Silva Cunha participou da análise, interpretação dos dados e redação.

interpretação dos dados, redação e revisão

\section{Como citar este artigo (Vancouver)}

Cunha ILR, Ferreira LA, Cunha JHS. Cuidados realizados pela equipe de enfermagem aos pacientes que sofreram queimaduras. REFACS [Internet]. 2017 [citado em inserir dia, mês e ano de acesso]; 5(3): 381-389. Disponível em: link de acesso. DOI:

\section{Como citar este artigo (ABNT)}

CUNHA, I. L. R.; FERREIRA, L. A.; CUNHA, J. H. S. Cuidados realizados pela equipe de enfermagem aos pacientes que sofreram queimaduras. REFACS, Uberaba, v. 5, n. 3, p. 381-389, 2017. Disponível em: <link de acesso>. Acesso em: inserir dia, mês e ano de acesso. DOI:

\section{Como citar este artigo (APA)}

Cunha, I. L. R, Ferreira, L. A., \& Cunha, J. H. S. (2017). Cuidados realizados pela equipe de enfermagem aos pacientes que sofreram queimaduras. REFACS, 5(3), 381-389. Recuperado em: inserir dia, mês e ano de acesso de Inserir link de acesso. DOI: 